\title{
Power Paola, cotidianidad y turismo
}

\section{Iván Pérez-Zayas}

\author{
Recibido: 15.09.2021 — Aceptado: 30.09.2021
}

\section{Titre / Title / Titolo}

Power Paola, vie quotidienne et tourisme

Power Paola, every day life and tourism

Power Paola, vita quoridiana e turismo

\section{Resumen / Résumé / Abstract / Riassunto}

En sus novelas gráficas, la artista de cómics colombiana Paola Gaviria (alias Power Paola) centraliza la representación de los espacios locales» que ella visita durante sus muchos viajes por el mundo. Con la ciudad y la selva, autopistas o sendas, bodegas y ciénagas puestos en la mirilla, el arte de Gaviria desarticula las fronteras que separan los lugares que sus personajes ocupan, ya sean espacios turísticos u ordinarios. Lo que queda expuesto en su obra entonces es un espacio nacional en donde lo público-trastocado por las preocupaciones de interacciones privadas - carece de los estereotipos de identidad que dominaban la historieta de la primera mitad del siglo veinte. Este ensayo describe los procesos mencionados (centralización y desarticulación), para luego demostrar cómo la novela gráfica de temas cotidianos podría parecer ausente de una propuesta política, aunque propone formas alternativas de entender la condición neoliberal a partir de intervenciones identitarias a los espacio-tiempos de la región latinoamericana.

Dans ses bandes dessinées, l'artiste colombienne Paola Gaviria (alias Power Paola) centralise la représentation des lieux local» qu'elle visite pendant ses voyages. Avec les images des villes et la jungle, les grandes routes et les voies, les magasins et le marais de sa concentration, l'art de Gaviria démonte les barrières que séparent les places touristiques et banales où ses personnages occupent. Ce qui s'expose dans son travail artistique c'est une version de l'espace national dans laquelle les interactions publiques (teinté avec les préoccupations des questions privés) manque des stéréotypes qu'ont avait dominés les bandes dessinées en Amérique latine à la première moitié du vingtième siècle. Cet essai décrira les processus mentionnées (la centralisation et le démantèlement) pour expliquer comment est-ce que la bande dessinée de sujet quotidien semble être absent de la politique, bien qu'elle propose une possibilité nouvelle de comprendre la condition néolibérale à partir de la perspective des identités nationales aux espace-temps en Amérique latine.

In her graphic novels, Colombian painter and comic book artist Paola Gaviria (aka Power Paola) centralizes the representation of the local» places she visits during her travels. With the cities and the jungles, highways and pathways, bodegas and swamps in her crosshairs, Gaviria's art dismantles the frontiers that separate both the touristy and mundane spaces her characters occupy. What is exposed in her work, is a version of national space in which public interactions (tinged with the preoccupations about private matters) strip away the stereotypes that plagued the Latin American comic strips of the first half of the twentieth century. This essay describes the processes mentioned above (centralizing and dismantling) to demonstrate how graphic novels invested in the representation of everyday life might appear as lacking an interest in the political realities of the world they capture, even though they propose alternative modes of understanding the neoliberal condition from the perspective of the national identities constituting the space-time fabric of Latina American.

Nei suoi romanzi grafici, la fumettista colombiana Paola Gaviria (alias Power Paola) centralizza la rappresentazione degli spazi locali» che visita durante i suoi numerosi viaggi in giro per il mondo. Con la città e la giungla, autostrade o sentieri, cantine e paludi sotto i riflettori, l'arte di Gaviria smantella i confini che separano i luoghi occupati dai suoi personaggi, siano essi spazi turistici o ordinari. Ciò che viene esposto nel suo lavoro è quindi uno spazio nazionale in cui il pubblico - toccato dalle preoccupazioni per le interazioni private — non ha gli stereotipi identitari che hanno dominato il fumetto della prima metà del ventesimo secolo. Questo saggio descrive i suddetti processi (centralizzazione e disarticolazione), per poi dimostrare come la rappresentazione dei problemi quotidiani nel romanzo grafico possa sembrare priva di una proposta politica, pur proponendo modi alternativi di intendere la condizione neoliberista dalla prospettiva delle identità nazionali che definiscono lo spazio-tempo della regione latino-americana.

\section{Palabras clave I Mots-clé / Key words I Parole chiave}

Paola Gaviria, comic, identidad nacional, turismo.

Paola Gaviria, bande dessinée, identité nationale, tourisme.

Paola Gaviria, comic, national identity, tourism.

Paola Gaviria, fumetto, identità nazionale, turismo. 
Ciudades, campos, barrios, junglas, autopistas y pirámides, todo tipo de espacio adquiere prominencia en las novelas gráficas de la artista y escritora colombiana Paola Andrea Gaviria Silguero, alias Power Paola. Nacida en Quito, Ecuador en el 1977 y criada en Quito y Cali, Colombia, Power Paola estudió Expresión Artística en la Universidad Javeriana de Cali y Artes Plásticas en la Fundación Universitaria de Bellas Artes en Medellín. Después de formar una carrera haciendo cómics, dando talleres de arte y exhibiendo su arte en ciudades como Sídney y París, Power Paola Gaviria reside y trabaja mayormente en Buenos Aires, donde colabora con revistas, organiza el colectivo de mujeres artistas Chicks On Comics» y moviéndose por América Latina para trabajar dibujando u ofreciendo talleres de arte. Sin embargo, es mayormente conocida por sus novelas gráficas de cotidianidad y viajes por el mundo. Destacarían Virus tropical (2011), QP: Éramos nosotros (2014), Todo va a estar bien (2015) o iNos vamos! (2016). En ellas captura las experiencias del día a día, por más repetitivas o mundanas que sean, de alguien que se crío y vivió viajando por el mundo occidental. La más conocida de estas, debido a su adaptación al cine animado, es Virus Tropical. Esta novela gráfica es una autobiografía que cuenta los eventos que dieron forma a su crianza trasnacional, pero son sus tres siguientes obras las que merecen un estudio coordinado, ya que juntas demuestran un interés marcado en la representación de la cotidianidad de sus personajes.

Después de una primera lectura, las tramas de las tres novelas gráficas que siguieron a Virus Tropical podrían parecer inconexas, pero todas combinan exploraciones sobre los ritmos habituales que conectan a la artista a su entorno-tomarse el café, salir a caminar, enseñar una clase-con un interés profundo por conocer otras culturas mediante el viaje, tipificando una relación paradójica entre los espacios del turismo y la identidad. $Q P$, por ejemplo, colecciona cómics dibujados entre el 2006 y el 2012, páginas de un diario de viajes que la artista primero publicó en línea sobre los paises y ciudades que la artista visitó o en los que vivió con el hombre era en aquel momento su marido. Luego, con Todo va a estar bien, la artista regresa a su pasado, a la década de 1990, para mostrar a sus lectores los pequeños momentos de vida diaria y aventura que marcaron un viaje a un congreso de periodismo en Lima, Perú, una temporada en Cali y San Cipriano y una visita a una tía en Medellín. Para iNos vamos!, Power Paola pone en práctica las lecciones aprendidas de esos proyectos anteriores, estrenando más experimentación formal. Publicada completamente a color, esta contiene los mismos momentos mundanos que caracterizan el resto de su práctica artística, pero con un interés aún más marcado en la cultura y folclore de los diferentes países latinoamericanos que ella ha visitado durante los años 2013 y 2014. Interponiendo simbología precolombina con textos en prosa y retratos de personajes secundarios y terciarios, iNos vamos! agranda el foco de sus narrativas, dejando el protagonismo de la autora en el segundo plano.

En los cómics que componen esta trilogía informal, los pequeños incidentes que rellenan los días de los personajes alteran lo que el lector puede entender por una experiencia de viaje. Aunque sus narrativas parecerían ser sobre el turismo en su superficie, sus profundidades revelan un interés en el simple hecho de estar, de ser un vecino cualquiera, uno más entre la masa. La artista se dibuja comprando vino en París, llorando el fin de una relación amorosa por las calles de Medellín y visitando el cementerio de trenes en Uyuni, Bolivia, pero provee poco contexto, brinca de país en país, barrio en barrio, obviando fronteras nacionales y desarticulando los comportamientos usuales del que viaja por placer (Fig. 1, 2 y 3). De esta forma, sus novelas gráficas proponen una nueva identidad paradójica para el turista, una que no depende del consumismo fugaz, obviando el simulacro abreviado o la experiencia folclórica del guided tour a favor de una integración a los ritmos de los espacios que su cuerpo ocupa. Esta relación curiosa que existe entre espacio e identidad en los cómics de Power Paola define a su vez los contornos de su versión de la trama doméstica, dislocando las versiones de identidad nacional que definieron los cómics e historietas de la época dorada del cómic latinoamericano a favor de un énfasis en una cotidianidad difusa pero significativa. 

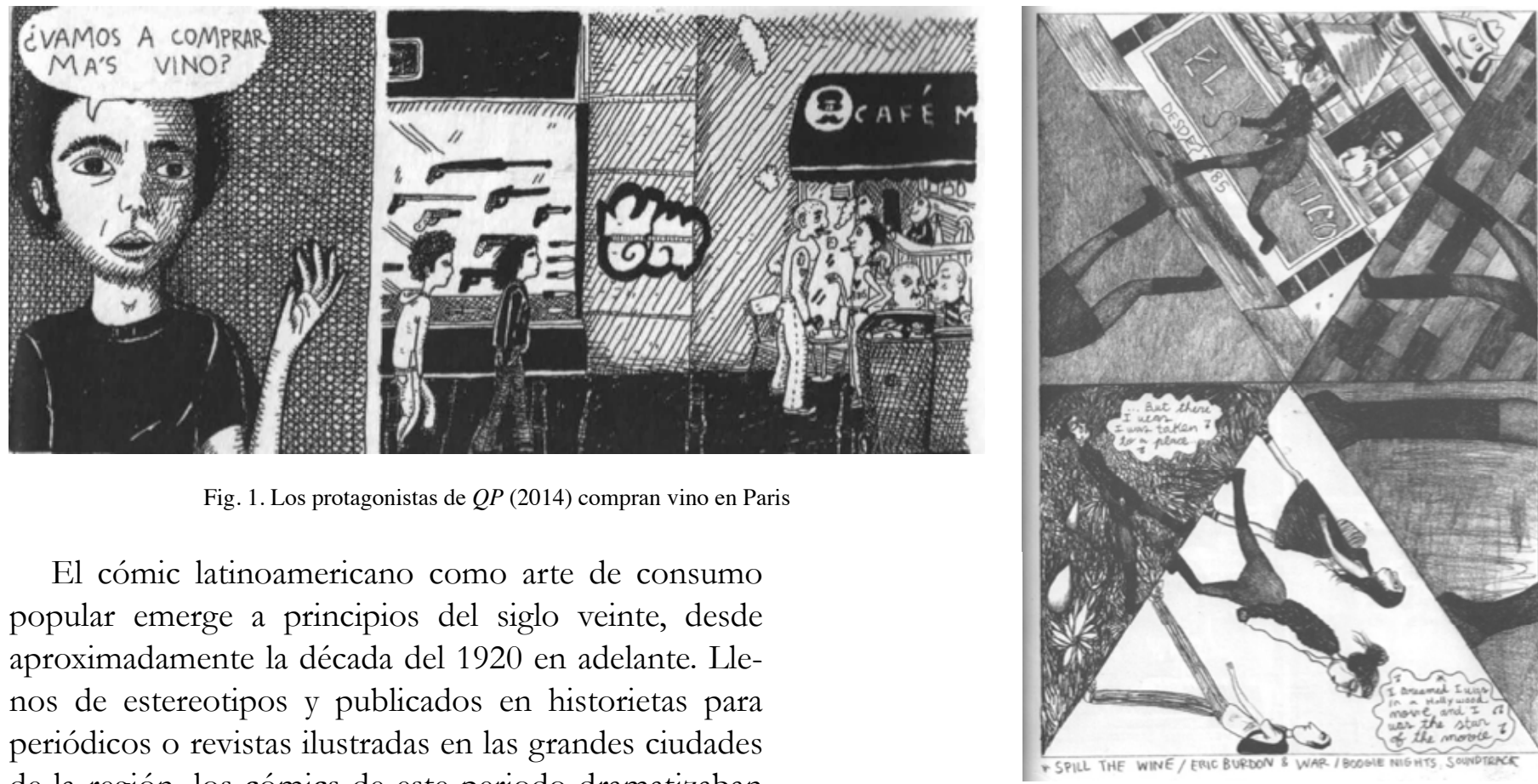

El cómic latinoamericano como arte de consumo popular emerge a principios del siglo veinte, desde aproximadamente la década del 1920 en adelante. Llenos de estereotipos y publicados en historietas para periódicos o revistas ilustradas en las grandes ciudades de la región, los cómics de este periodo dramatizaban diferentes discursos de identidad nacional a través en gran parte de imágenes y narrativas jocosas sobre dramas domésticos y urbanos, esparciendo ideas sobre la modernización, desarrollismo y cambios drásticos en densidad poblacional de las ciudades que definieron el siglo veinte latinoamericano (L'Hoeste y Poblete, 15). Los primeros historietistas significativos de Colombia comenzaron sus carreras durante el mismo periodo y propagaron ideas similares.

En el 1924, por ejemplo, el caricaturista Adolfo Samper creó la historieta Mojicón» bajo la dirección de Arturo Manrique para el periódico Mundo al día. El primer personaje recurrente de la historieta colombiana, Mojicón era un niño travieso cuyas ocurrencias ambientadas en la capital eran, en un principio, versiones plagiadas de historietas estadounidenses como Smitty y Gasoline Alley. La tirilla Mojicón» sería cancelada durante la década del 1930, víctima de la crisis económica que aquejaba a varios países en las américas durante

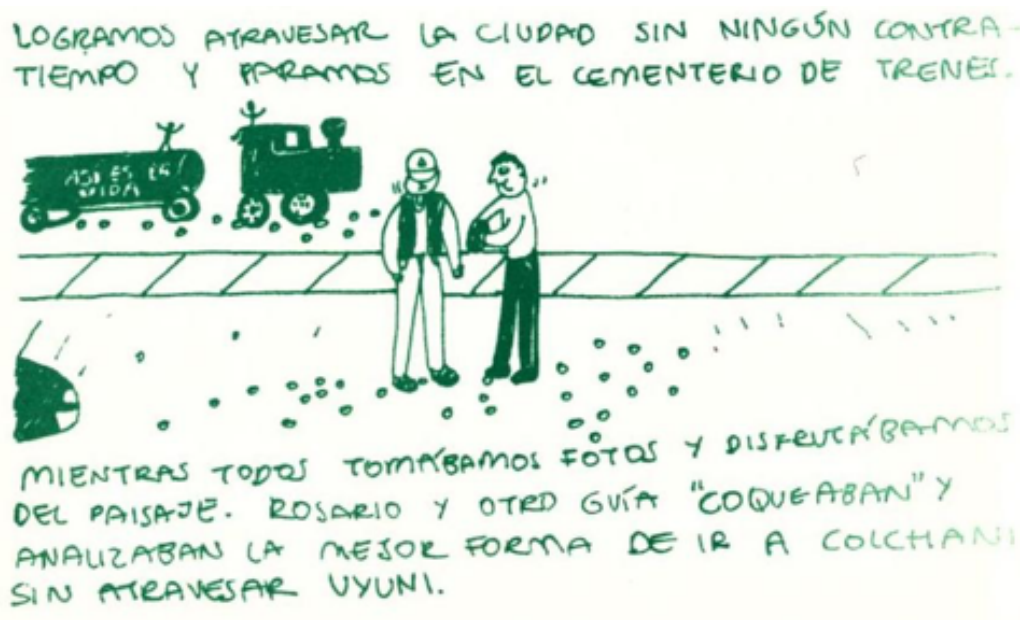

esos tiempos. Años después, insatisfecho con la falta de originalidad de su primera creación, Samper logró un segundo éxito profesional con las historietas Don Amacise» y Misia Escopeta» (Fig. 4 y 5), publicadas en la revista Sábado» durante la década del 1940 (Guerra). Las peripecias de los personajes titulares -Don

Power Paola camina por Medellín en Todo va a estar bien (2015) 


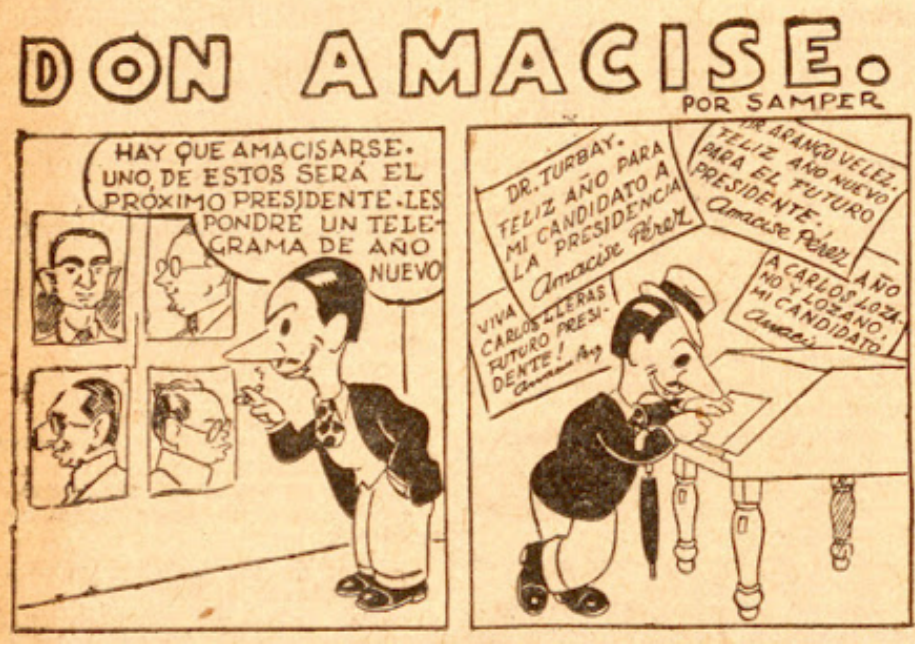

Fig. 4. Don Amacise, aparecido en la Revista Sábado, busca el favor de los políticos ( $1^{\text {ro }}$ de enero de 1944)

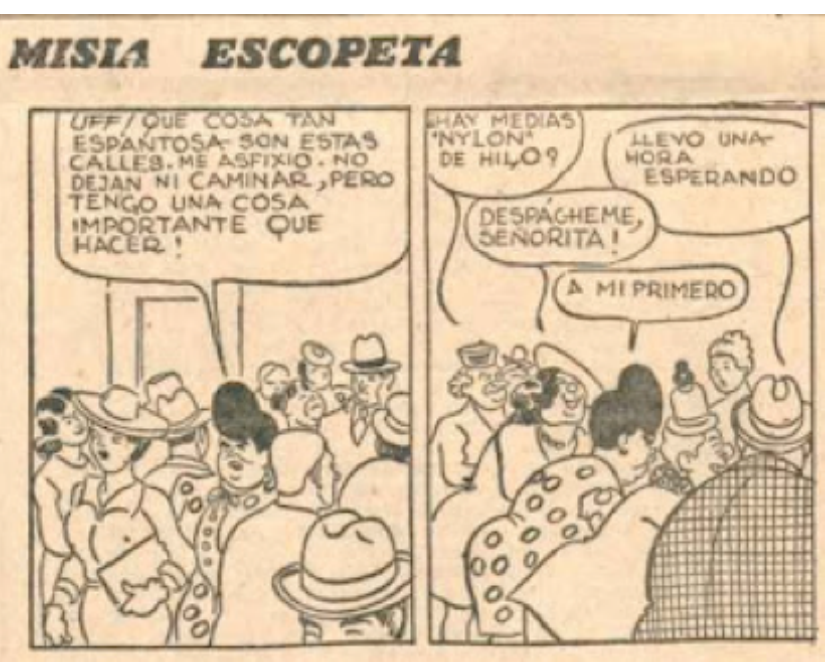

Fig. 5 Misia Escopeta se codea con otras mujeres en la ciudad (Revista Sábado, 4 de mayo de 1946)
Amacise el tinterillo o picapleitos y Misia Escopeta la solterona- se inspiraban en su identidad como tipos supuestamente particulares a Bogotá, terminando de ganarle a su creador eventualmente el título del padre de la historieta colombiana» (González Aranda). Luego, en el 1962, mucho después del debut de Don Amacise y Misia Escopeta y durante el periodo de la masificación del cómic latinoamericano, Ernesto Franco creó el personaje de Copetín para el periódico El Tiempo». Este otro episodio importante de la historieta colombiana también presenta a sus lectores la vida en bogotá, pero esta vez desde la perspectiva de un niño pobre y desamparado; Gamín» es la palabra que se usaba en ese tiempo en Colombia para describir a los niños de la calle (Hernández).

Paradigmas de la evolución que caracterizó la formación difusión del cómic latinoamericano durante el siglo veinte, los personajes Mojicón, Don Amacise, Misia Escopetica y Copetín son retratos de la vida metropolitana en Colombia, historias costumbristas que impartían al lector ideas sobre la nación y quienes podía uno esperar encontrarse en sus barrios. Estos personajes, sin embargo, no contextualizan solamente el origen del cómic colombiano en relación a la historia del medio en la región, sino que también ejemplifican como el medio en si entabla desde un principio un diálogo con su público, complicando lo que entendemos por identidad nacional. Si la iconografía nacional resaltaba la homogeneidad en la creación [y representación] de una esfera pública nacional y singular,» explican los estudiosos de este momento crítico en la historia del cómic latinoamericano, Hector Fernandez L'Hoeste y Juan Poblete, la popular explotaba en sinnúmero de formas, manifestando la heterogeneidad de la ciudadanía» (4). Los cómics del siglo veinte no nadaban en contra de la corriente de los monumentos y narrativas del estado sobre la identidad nacional con sus personajes pobres, jocosos, entrometidos y politiqueros, sino que era durante su difusión a las masas que dejaban la puerta abierta para una pluralidad de interpretaciones sobre la identidad representada. Power Paola retoma esa tradición, modificando y expandiendo su habilidad para capturar la colombianeidad, una identidad que da cuenta de los cambios que traen la globalización y el capitalismo tardío a América Latina mediante sus historias sobre el viaje y la cotidianidad.

Las ideas sobre identidad en las que el cómic colombiano del siglo veinte trafica no son entonces un fenómeno singular sino que forman el principio de una tradición narrativa, una tradición a la que los cómics de Power Paola pertenecen. Los mercados en los que se mueve los cómics de la artista contemporánea (y el pú- 
blico que los consume) habrán cambiado, pero el interés de representar aquello que el imaginario popular entiende como experiencia común y corriente del colombiano o latinoamericano promedio sigue en efecto. En otras palabras, aunque las ganas de representar los hábitos de la gente colombiana ha sido el trabajo del cómic desde un principio, estudiando las obras de Power Paola en conversación con las de Samper y Franco marcamos cambios en el discurso. La cotidianidad que se desborda hasta llenar los espacios públicos en obras como $Q P$, Todo va a estar bien y iNos vamos! cambia la perspectiva del lector sobre lo que es el uso o propósito primordial del turismo. $\mathrm{Y}$ es que esas tres novelas gráficas trasforman la página del cómic en una heterotopía - concepto foucauldiano que define las cualidades de los espacios cotidianos - para proveer ejemplos de una nueva forma de relacionarnos con culturas a las que no pertenecemos mediante el viaje trasnacional.

\section{Cotidianidad que se desborda}

La intrincación entre identidad y espacio que caracteriza los cómics de turismo que Power Paola crea se asemeja a la «heterotopía», concepto que Michel Foucault inventó para describir algunos espacios comunes y corrientes a la vida durante siglo XX que él encontraba importantes distinguir de los espacios de la utopía. Para Foucault las utopías son sitios que existen pero no se manifiestan en lugares concretos del mundo, algo como versiones mejoradas pero inexistentes de las sociedades en que vivimos. A partir de esa definición, el filósofo francés propone usar la heterotopía para categorizar a aquellos espacios ordinarios que adquieran nuevos sentido en relación con otros lugares de su mismo tipo. Por ejemplo, según Foucault, los colegios militares pueden ser heterotopías porque históricamente los colegios militares» funcionan como categoría de espacio que cambia con el tiempo y uso, un sinnúmero de distintos edificios que se repiten con variaciones particulares pero que generalmente albergan adolecentes pasando por la pubertad y entrenándose en un número especifico de conocimientos bélicos. Similarmente, la categoría jardín» entonces serviría para unir inextricablemente el jardín de cualquier casa con el jardín botánico de la ciudad, convirtiendo así la categoría general (jardín») en un lugar que es a la vez dos sitios en uno, un archivo conceptual para todos los jardines. El colegio militar, el jardín, el cementerio, el festival, y muchos otros sitios por los que transitamos son entonces heterotopías, lugares que se oponen a todos los demás y que de alguna manera están destinados a borrarlos, compensarlos, neutralizarlos o purificarlos» (Foucault, 3). Las heterotopías son entonces espacios reales, cotidianos, heterogéneos y polivalentes cuyo significado cambia con el pasar de los años y la circulación de gente. El estudioso del cómic latinoamericano David William Foster, provee una interpretación de la heterotopía que afina el concepto de forma útil.

Las heterotopías no sólo son espacios reales, sino que pueden ser espacios hasta cotidianos y habituales. En su ensayo The Bar as Theatrical Heterotopia: José Muñoz and Carlos Sampayo's El Bar de Joe», David William Foster utiliza el concepto de Foucault para describir mejor la representación de bares y pubs en el ciclo de cómics Historias del bar de los argentinos José Muñoz y Carlos Sampayo. Según Foster, el bar representado en los cómics de Muñoz y Sampayo funciona como heterotopía para todos los bares genéricos, el grado cero de lo ordinario: a lived human space that is supersaturated with meaning, one that is marked off, along any one or several sociosemantic axes, from the ordinary or everyday realms of human events, which do not immediately evince supersaturated meanings or relationships» (20). El bar de Muñoz y Sampayo es un espacio genérico, supersaturado de significado por el sinnúmero de experiencias ordinarias que toman lugar entre sus paredes. Esta versión del concepto de Foucault esclarece cómo la página del cómic se puede convertir en heterotopía, en una colección de espacios de la cotidianidad, y los cómics de Power Paola se inclinan en esa misma dirección. Se ambientan muchas veces al aire libre o en espacios públicos y genéricos como la 
calle, los cafés y autobuses. Como demuestran poca acción y pocas veces centralizan la comedia propiamente, lo rutinario los define. Sus historias comienzan además en medio del asunto y son a primera vista inconexas o inacabadas, transformando sus proyectos en antologías envés de novelas» propiamente, en colecciones de mundanidad. Es de forma antológica y fragmentaria que los momentos cotidianos en la vida de sus personajes se acumulan, poco a poco dejando ver al lector una imagen completa. La imagen que los cómics de Power Paola dejan ver al lector es una en la que los protagonistas logran vivir en todas partes del mundo obviando los rasgos más obvios o comunes a las narrativas de viaje: el movimiento y la transición. La transición entre un lugar y otro se elide, se confunden los espacios urbanos unos con el otro y sus paisajes se entremezclan. Grafiti y brea, ladrillo, farol, borrachos y cafés, todo parece dar igual. Y es que todo espacio público, ya sea en Colombia, Perú, Australia o Francia, sirven todos como contenedores de cotidianidad cuando Power Paola y sus personajes conversan y conviven. Como los bares de Muñoz y Sampayo, las ciudades, campos, barrios, junglas, autopistas y pirámides de Power Paola son primero que todo receptáculos para lo común y corriente de las actividades que definen la acción. Su arte convierte hasta las vías y caminos de centros de turismo y cultura reconocidos mundialmente (como Paris o Machu Picchu) en trasfondos para preocupaciones mundanas, cambiando el significado o simbolismo de lo que son normalmente lugares súper-saturados de significado mediante una energía de carga opuesta: eventos que carecen de súper-saturación. Un análisis cuidadoso de algunos momentos paradigmáticos en las novelas gráficas QP, Todo va a estar bien y iNos vamos! demuestran como la obra de Power Paola está intensamente enfocada en la interacción los espacios que ambientan la acción de sus personajes, la cotidianidad, y la experiencia de ser un turista.

Presentado como un cuaderno esbelto de capa blanda, $Q P$ tiene el tamaño de una libreta; gracias a sus portadas suaves podrías cargar su colección de relatos nómadas a todas partes. Son páginas de un diario de viaje rellenado de forma apresurado, esta novela gráfica no parece seguir un orden riguroso. Sus primeras tres historias no guardan relación mayor unas con las otras. Hasta su arte, experimental y cambiante, refuerza el sentido improvisado de esta construcción narrativa relajada. El diseño de sus personajes y el trazo del lápiz incluye dos o tres estilos de dibujo diferentes, especialmente en la primera mitad de la novela gráfica. Esta historia multiforme sirve además para comenzar a definir la relación que aguarda la representación de momentos cotidianos en las obras de Power Paola con los espacios del viaje que ambientan la mayoría de sus cómics.

Los primeros tres cómics de QP son todas historias de una sola página. Cada una de ellas ejemplifica las pequeñas interacciones mundanas que definirán la vida nómada de los protagonistas, la Q y P del título. Todo comienza en Saturday Morning» con una simple rutina mañanera en la que P se despierta, se cepilla los dientes y se arregla el pelo en el baño, tan solo para regresar a la cama con $\mathrm{Q}$, hacer el amor y volver a despeinarse. Las letras pequeñas de la palabra end»—ovilladas en la esquina inferior derecha del último encuadre-le ponen un final susurrado a la escena. Las páginas de QP (y las demás obras de Power Paola) están llenas de momentos así, tiernos, rutinarios y fugases. La próxima historia, Algo Abrupto», encuentra a los personajes en el exterior, pero refuerza el tono íntimo. Vestidos para el frío del invierno, Q y P comen hotdogs en un café al aire libre. El primer encuadre es un primer plano de un árbol sin hojas. El segundo es un plano americano en el que ambos Q y P se llenan la boca con comida. ¿Que piensas? ¿Todo bien?», le pregunta $\mathrm{P}$ a su pareja en el próximo encuadre. Necesito que algo pase con mi vida. Algo abrupto...», Q le contesta melancólicamente. Justo en el momento de silencio sugerido por los puntos suspensivos un pájaro posado arriba de los chicos, en uno de los arboles que enmarcan la escena, deposita excremento sobre el almuerzo de Q (Fig. 6). La historieta acaba con un encuadre que enfoca su comida arruinada, no incluye las reacciones de los protagonistas. Sunday 6PM» tiene el mismo ritmo y tono soñoliento de esas primeras dos historias: P prepara la bañera con agua caliente; se acues- 
ta en ella con los ojos cerrados. Q se le une, gimiendo cuando sus piernas peludas sienten por primera vez la temperatura extrema que su pareja prefiere. ¿Sabes? Yo creo que deberíamos tener una vida más activa», dice la chica. De acuerdo», le contesta el chico. Y otra vez, una conclusión sin comentario, casi sin desenlace.

Historias como estas transforman la página del cómic en el espacio ideal para explorar una cotidianidad que comienza en el hogar, pero se deja sentir en todas partes, se desborda hasta solapar las fronteras del espacio privado cubriendo o llenando los espacios públicos. El resto de la novela gráfica lo confirma. En la historia titulada Carmelo», Q y P se sienten responsables de un perro callejero que los acompaña mientras caminan las calles de la ciudad Uruguaya del título. Luego, en Atracción fatal», los mismos persona-
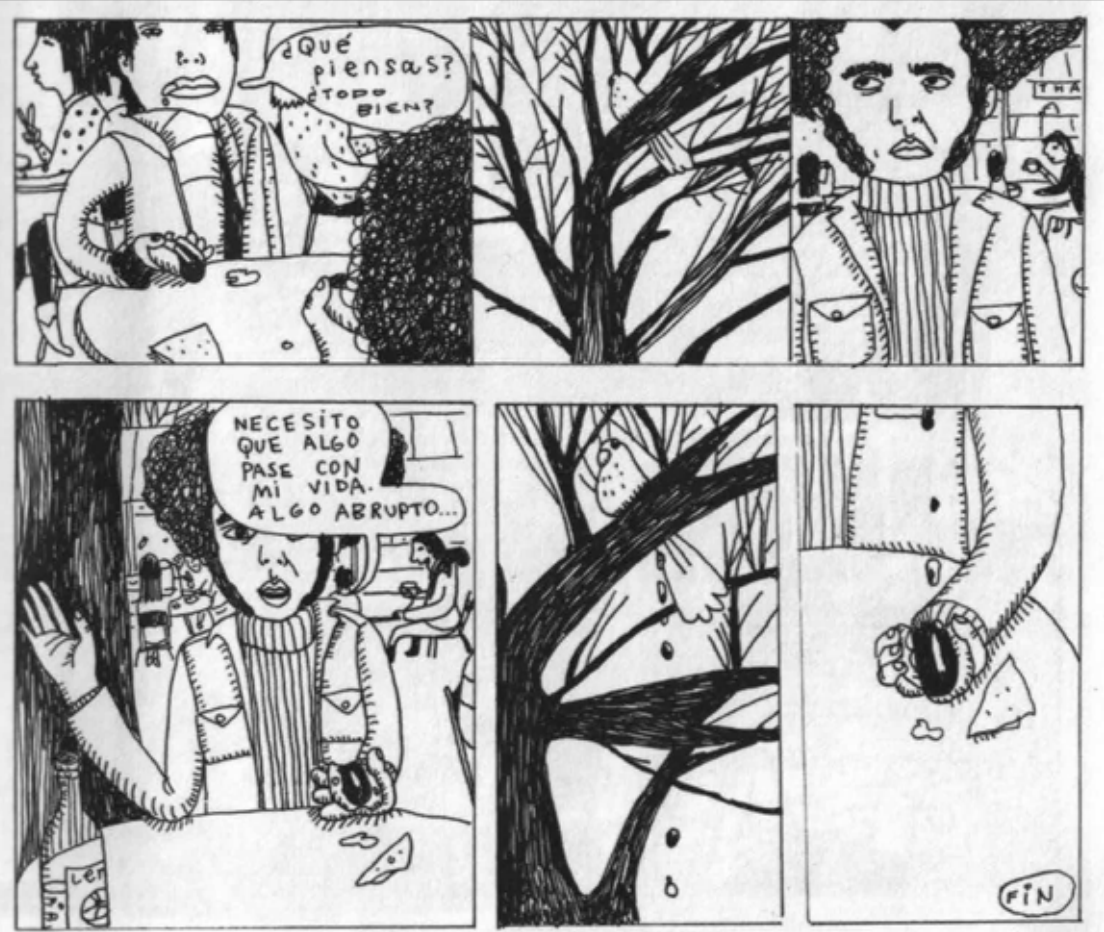

Fig. 6. P y Q traen los pormenores de su día a un espacio público, QP: Éramos nosotros (2014) jes beben vino y comen crepas, sentados al borde del río Sena, pero cada vez que P se queda sola - en lo que Q va y busca copas para el vino o crepas de Nutella para el postre- alguien se le acerca a P para darle conversación. Más tarde, en el El Centro», Q y P visitan a la hermana de P en San Salvador. Caminando una vez más por la calle, los protagonistas encuentran que la escena de un tiroteo interrumpe su hábito de ambular; hasta la violencia de las maras se convierten en parte del día a día. La cotidianidad de Q y P es una que siempre sale a pasear, a decorar todo tipo de ciudad de pequeñas preocupaciones. Todo va a estar bien y iNos vamos! incluyen relatos que logran efectos similares, más extensos en la primera novela gráfica y más breves en la segunda.

Presentadas en forma de libreta gorda de capa blan$\mathrm{da}$, las historias de Todo va a estar bien son extensas y están organizadas en capítulos. El estilo de arte que las caracteriza es más constante, ya que son dibujadas con el mismo trazo de lápiz y sus encuadres no llevan entintado. Más importante aún, demuestran cómo el desbor-

de de la cotidianidad que caracterizaba a $Q P$ no afecta solamente a las calles anónimas de las ciudades por las que la artista ha deambulado, sino que crea heterotopías de los lugares de turismo más concurridos también. Su introducción es además un cómic autobiográfico más tradicional en comparación a las resumidas escenas que caracterizaban a la novela gráfica detallada anteriormente, pero esta sin embargo continua la exploración de la cotidianidad del viajero con historias de finales truncados y fugaces. Titulada El Viaje», ese primer cómic está ambientado en Perú para mediados del 1990, durante una estadía extendida que tuvo Power Paola en el país suramericano. Este se extiende de forma ininterrumpida por más de treinta páginas que incluyen acción ascendente, clímax y desenlace que cuentan sobre el florecimiento breve de una amistad. Otro elemento que diferencia la primera historia de Todo va a estar bien de las historias breves de $Q P$ es que, desde un principio, El Viaje» se centra en la experiencia de Power Paola, ya que la artista narra en primera persona sus sentimientos 
sobre lo que se cuenta, brindando contexto mediante cartelas de monólogo interior. Sin embargo, aunque esta historia contiene elementos narrativos más tradicionales que los de $Q P$, sus encuadres dependen igual de la heterotopía para prestar coherencia a sus versiones del espacio marcado por lo ordinario.

El Viaje» comienza en el cielo, mientras Power Paola y su amiga Mara vuelan camino a un congreso de periodismo en la Universidad de Lima por aerolínea comercial. Las chicas aterrizan y salen del aeropuerto conversando entre ellas en los primeros encuadres. Mientras tanto, la narración en cartelas reflexiona: Era la primera vez que viajaba a Perú...Yo no estudiaba para ser periodista pero mi amiga Mara sí. El pasaje salía muy barato y era mi oportunidad para conocer Lima y Cuzco» (34). En el auditorio donde comienzan las actividades del congreso, las chicas se fijan en un joven guapo que le toma fotos al público y la narradora comenta sobre la cantidad de latinoamericanos que hay. Ya afuera del auditorio, Power Paola y Mara van por sanduches de palta, huevo y queso en el campus universitario. Almorzando conocen a Juan, el fotógrafo atractivo. Mara primero explica de dónde son ella y su amiga Paola: De Colombia....Bueno Paola es Colombo-ecuatoriana. ¿Y vos?» Yo soy de acá Pe...», contesta Juan, interrumpido por un cambio de escena en el próximo encuadre (10). Desde esa interrupción en adelante, la conversación continua pero las palabras son substituida por un diálogo que no se puede leer, burbujas llenas de líneas deformadas y risas envés de palabras e ideas. Durante esa secuencia

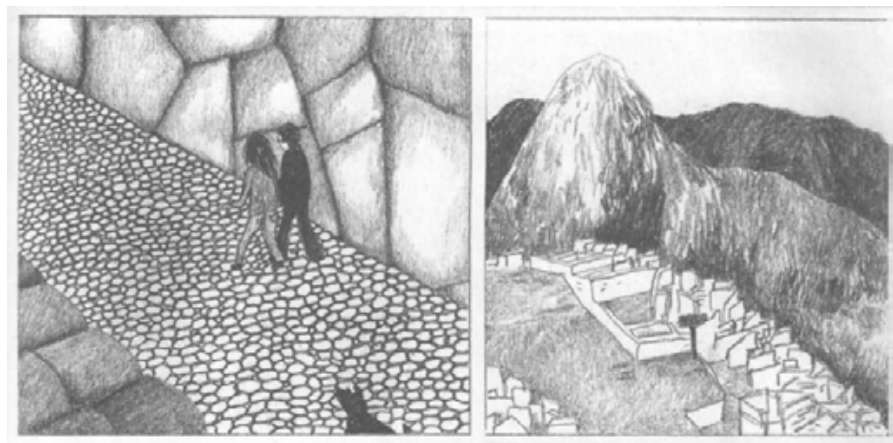

Fig. 7. las figuras casi anónimas de Power Paola y Mara andn por Macchu Picchu, Todo va a estar bien (2015) de diálogos ilegibles, los encuadres del cómic desaparecen y las chicas y su nuevo amigo se mueven ininterrumpidas desde el área verde donde se conocieron a una colina donde conversan y dibujan, luego a almorzar alrededor de una mesa y finalmente, a tomar fotos por la ciudad. La cotidianidad de la conversación y el almuerzo rebosa una vez más los espacios de ambientación, la página del cómic se llena de espacios públicos marcados por momentos privados. Este proceso se repite cuando mas tarde en la misma historia Power Paola y Mara dejan a Juan en Lima brevemente para visitar juntas a Machu Picchu.

Con la segunda secuencia sin diálogo de El Viaje» el lector solo tiene entre mano unos breves retratos que resumen lo experimentado por los personajes durante una visita a Cuzco y Machu Picchu: un avión que aterriza de noche, dos mujeres quechuas que recalcan la importancia de tomar té de coca, las pequeñas figuras de Power Paola y Mara caminando por calles adoquinadas vistas desde lejos (Fig.7), sus sonrisas mientras ellas comen choclo, una llama, etc. Las aventuras de los personajes de Todo va a estar bien son resumidas entonces de dos formas, con brincos y saltos de un lugar a otro, diálogos que desaparecen y transiciones que se eluden, heterotopía que conecta eventos difusos entre si. Como en $Q P$, las experiencias de Power Paola la viajera son presentadas otra vez sin pompa ni fastuosidad, resumiendo la experiencia de permanecer en Lima y Cuzco mediante un puñado de imágenes callejeras alteradas en donde la mundanidad es enfatizada y los placeres usuales del turismo se dejan en el trasfondo o escurren como arena entre los dedos, efecto que crea una relación entre ambiente y actividad en la que las fronteras entre un espacio y otro desaparecen gracias a la cotidianidad de la trama. Irónicamente, los espacios públicos de la narrativa del viaje se convierten en genéricos mediante eventos que tampoco llevan una súper saturación de significado. ¡Nos Vamos!, una de las novelas gráficas más recientes y ambiciosas de Power Paola, contiene cómics que detallan un segundo viaje a Machu Picchu. Similarmente sencilla y fugaz, ésta afina la actitud ambigua 
o paradójica que mantienen las obras de Power Paola frente a la identidad y experiencia del turista.

La edición colombiana de ¡Nos Vamos! es de tapa dura y a todo color, reflejo quizás del éxito profesional que Power Paola se ha ido asegurando poco a poco. Los dibujos de esta novela gráfica, a diferencia de las dos anteriores, no son creados con lápiz solamente, sino que están entintados con una amplia gama de colores neón. Sus impresiones en verdes, rosados y naranja de Tupiza y Potosí en Bolivia o de Ushuaia y Umahuaca en Argentina, por ejemplo, se entremezclan con retratos de amigos y desconocidos encontrados en la calle, recuentos surreales de los sueños de la artista, y apuntes sobre valijas y pictografía indígena. Estos viajes y aventuras por América Latina son, otra vez, anclados por pequeños momentos de conversación y aburrimiento. El viaje es incorporado a la estructura narrativa a través de sus pausas nuevamente. Nada de momentos épicos o panorámicos.

Otra historia ambientada en Machu Picchu subraya esta curiosa versión del turismo. Titulado Perú: Cuzco» y fechado para el 28 de Julio de 2014, ¡Nos Vamos! incluye un cómic dedicado a otra visita que hizo Power Paola a la ciudad del título, esa que recibe tantos y tantos extranjeros rumbo a Machu Picchu. Esta vez, la historia es de siete páginas y hace texto de eso que las otras dos novelas gráficas mantienen como subtexto: hay formas de viajar el mundo sin ser un turista, sin hacer exotismo o tratar como objetos a las culturas con las que se interactúa, evitando participar de las economías consumistas. En la combinación de su arte y texto descubrimos su actitud frente a los detalles que forman la experiencia de visitar a un lugar tan histórico y concurrido como la ciudad Inca. El arte de Perú: Cuzco» es entintando en color rosado y no tiene encuadres. La introducción enmarca a los protagonistas, quienes parecen flotar entre las palabras (63):

Llegamos a las 4AM después de un viaje de 9 horas de Copacabana (Puno) a Cuzco. El primer bus fue común y corriente, en la agencia de Titicaca Bus nos lo habían vendido como un bus semicama...Por suerte, aunque todo fue muy loco, nos montaron en [sic] bus muy cómodo que no hacía tanto frío y quedamos profundamente dormidos.
Como es de costumbre en los cómics de Power Paola, el narrador de iNos Vamos! enfatiza primero la mundanidad que caracteriza los viajes de la artista. La secuencia de imágenes que la acompaña, subraya lo mismo. Cargando con bolsas de acampar y de mano, la versión dibujada de Power Paola conversa con quien es en esta ocasión su pareja de viajes, una persona dibujada con cabeza de canino, identidad caricaturesca que salvaguarda su privacidad. Che, y qué hacemos a esta hora.», pregunta el acompañante de Power Paola. Quedémonos como casi todos los gringos esperando a que amanezca», le contesta la artista. Luego, en el siguiente dibujo aparecen los dos otra vez, ahora sin equipaje pero con sombreros y chamarras, tratando de calentarse con la ayuda de un té. Qué bueno que vendan mate de coca con hojas de acá en la estación», comenta el acompañante. Mmmmhh siii», añade Power Paola. Después de otra secuencia similar en la que Power Paola se baña con agua fría y detalla las miserias de viajar con poco presupuesto (Siempre falta algo! O wi-fi o agua caliente o hace frio»), la acción se mueve a Cuzco. En la siguiente página, una imagen solitaria sirve de transición, cambiando la textura visual del cómic. La historia ya no se cuenta con secuencias, sino que lo hace con retratos individuales.

El retrato de transición que señala el desenlace de Perú: Cuzco» contiene dos figuras. Su interrelación con la heterotopía incluye un comentario sobre el turismo (Fig. 8). La primera figura es una mujer quechua, con su niño en la espalda, sentada al lado de una llama y al borde de una de las calles adoquinadas de Cuzco, ofrece los servicios turísticos a quien pueda escucharla: Tomame [sic] una foto con mi llamita». Mientras tanto, en el segundo plano de la misma imagen Power Paola camina por su cuenta y piensa, Me gusta viajar, pero odio ser turista» (65). Varias pancartas y anuncios pegado a una puerta completan la escena. Estas leen Money Exchange», Tour to Machu Picchu» y Entrance fee to Huayna Picchu», resaltando como el turismo no está pensado con visitante latinoamericanos como la artista en mente ni beneficia a la población indígena a la cual la mujer quechua pertenece. Para la conclusión de la historia, re- 
gresa el espacio sin fronteras a la página. Después de describir una vez más las frustraciones del bus económico, y los hostales, Power Paola añade a su lista las caminatas y la ropa que lleva puesta por quince días corridos, frustraciones que exacerban el cansancio de un viaje que ni siquiera rindió fruto: En total nos quedamos 3 días en Cuzco. No pudimos ir a Macchu Picchu estaba lleno de turistas y no había posibilidad de subir en tren. Yo no tenía muchas ganas de hacer el tour en carro por 2 días, estaba agotada con tanto turismo» (69)

Perú: Cuzco» es una historia de un turismo» frustrado; sin llegar a las vistas panorámicas de la ciudad Inca, lo que queda en su lugar es una vez más el resto de los momentos indefinidos y fugaces del día a día. Igual que en el Paris de QP y el Lima de Ahora todo va a estar bien, Cuzco se convierte en nada más que un puñado de ca-

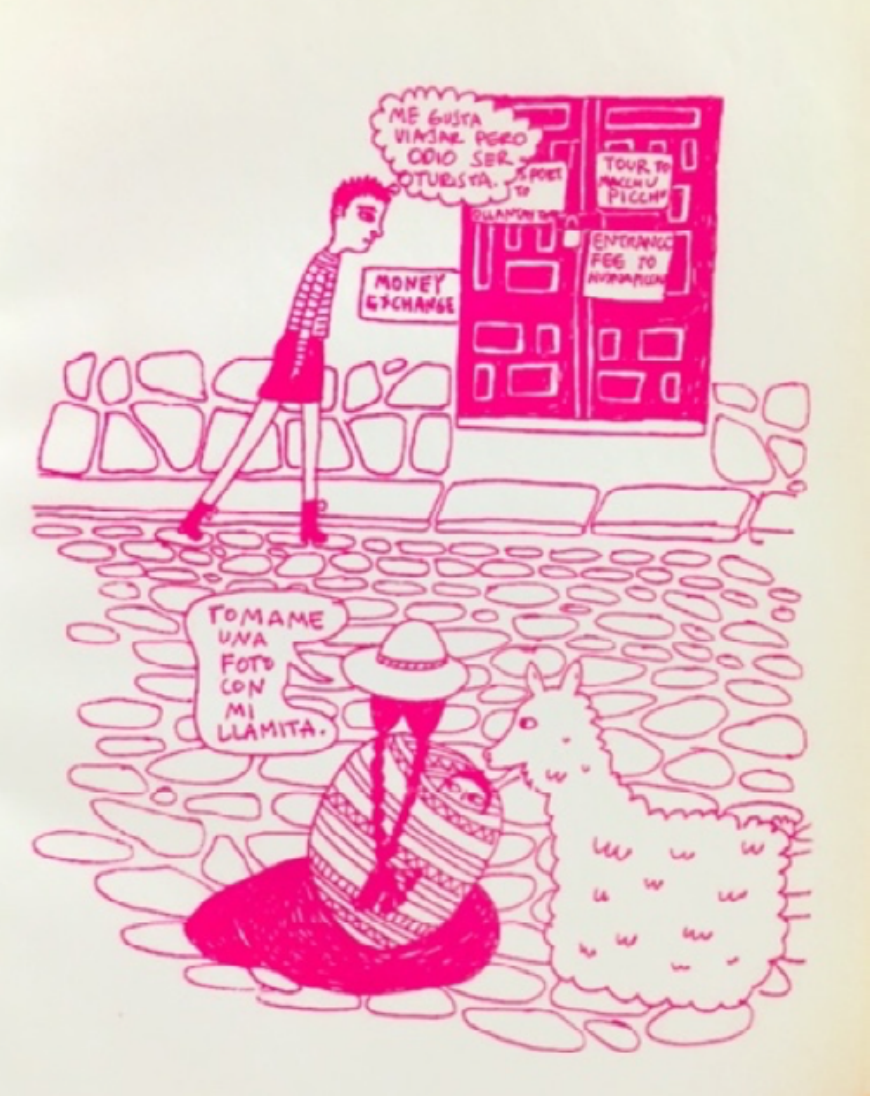

Fig. 8. Las figuras casi anónimas de Power Paola y Mara andn por Macchu Picchu, Todo va a estar bien (2015) lles, de caminatas y conversaciones sin desenlace obvio o resolución emocionante. La heterotopía de la metrópolis cubre una vez más las páginas con representaciones de espacios públicos afectados por la intimidad que se desborda desde la vida interior o personal de Power Paola hasta trasformar el turismo, y sus espacios supersaturados de significado y emoción, en el grado cero de lo ordinario. Las heterotopías de Power Paola sin embargo, no se forman sin razón, sino que conversan con la historia del cómic de siglo veinte y sus discursos de identidad, ya que sirven para cuestionar la relación que existe entre el turismo y el privilegio de clase, haciendo una propuesta desde una perspectiva burguesa que por lo menos imagina formas de moverse a través del mundo más allá que las propuestas por el capitalismo tardío y globalizado.

\section{Heterotopía que forma}

A Small Place (1988) es una colección de ensayos breves con los que Jamaica Kincaid examina la catastrófica estela que dejó el colonialismo europeo en las antillas y como estas consecuencias se reflejan en los privilegios de los que vacacionan en su país de origen, Antigua. Su descripción de cómo el turista va y viene mientras que una gran parte de los ciudadanos nativos de los lugares a los que se viaja no tienen ese lujo sirve para mejor entender lo que la heterotopía de Power Paola logra cambiar sobre las narrativas de turismo (18):

Every native would like to find a way out, every native would like a rest, every native would like a tour. But some natives - most natives in the world - cannot go anywhere. They are too poor.

El privilegio de clase que Kincaid detalla, uno de libertad de movimiento que separa al turista del nativo, describe parte de la experiencia que caracteriza a los personajes de Power Paola. Aunque las obras de la artista colombiana resaltan como sus viajes fueron producto de oportunidades laborales de poco lucro o son definidos por un presupuesto limitado, ver el mundo 
como artista o maestra itinerante como quiere requiere un grado de profesionalización o libertad fiduciaria que no es acequible a grandes partes de la población latinoamericana. Power Paola, sin embargo, no ignora esas implicaciones. Si es cierto que una gran parte de las tres obras estudiadas en este ensayo son narrativas de turismo, también es cierto que a la artista no le interesa consagrar o celebrar dicha experiencia. Además, los puntos de referencia turísticos más obvios de los países que Power Paola visita, casi nunca aparecen en sus cómics y si aparecen, son como sus dos versiones de Machu Pichu, lugares sobre los que la narrativa no indaga, representaciones que no sorprenden ni crean incidentes iniciadores, clímax o desenlaces obvios. Son en vez puro mise en scène y transición ligera. Favoreciendo la heterotopía, sus versiones del espacio turístico entonces funcionan principalmente como recipientes de experiencia individual, momentos que recalcan como las interacciones ordinarias pueden llegar a definir el tiempo que sa pasa viajando. Sus estadias más extensas en Paris o Buenos Aires están llenas de momentos tan fugaces y ordinarios como sus visitas breves a la amazona colombiana. Y esto es porque, los cómics de Power Paola depende del lector que va a encontrar interesante sus vacíos y a quien no le interesa el kitsch consumista del turismo.

Con la heterotopía, los lugares que el turista visita y las experiencias que consume como producto de una economía capitalista y globalizada son transformados en una propuesta sobre lo que puede significar ser ciudadano del mundo, promoviendo una nueva forma de relacionarse con la pluralidad de identidades que ocupan la región latinoamericana. En todas, el espacio privado se desborda, las actividades mundanas llevan a los protagonistas_-Paola, sus parejas y amigos_-desde la sala a la calle, al mercado, a la jungla y de vuelta a la sala, desvaneciendo las fronteras entre un espacio y otro de tal forma que el lector se queda con la impresión de que lo más valioso del viaje es el simple hecho de poder existir en otras comunidades, de encontrarse caminando al lado de personas con experiencias de vida diferentes a las de uno y no la oportunidad de consumir cultura me- diante los monumentos oficiales que el estado declara turísticos. De esta forma, el grado cero de lo ordinario propone una identidad nómada que se contrapone a los discursos de identidad nacional que definieron la época dorada del cómic latinoamericano.

Contraponer esta nueva versión del turista con la identidad nacional propuesta por las historietas colombianas de la primera mitad del siglo veinte nos deja ver cómo actitudes sobre lo que se puede conocer o no sobre la nación y su gente mediante el cómic ha cambiado drásticamente con la proliferación de novelas gráficas de autor de fin de siglo, cambio presagiado a su vez por el boom de los cómics alternativos de los sesenta y setenta del pasado siglo. Especialmente considerando cuanta influencia han tenido las historietas sobre vida, trabajo, género, sexo y otros temas íntimos y experimentales del cómic alternativo sobre las obras de Power Paola. Este cambio fue ejemplificado en publicaciones como las de Wimmen's Comix», la serie de cómics de más larga publicación hecha completamente por mujeres que abrió el camino para otro sinnumero de historietistas femeninas. La ambivalencia que define la representación del viajero en Power Paola es totalmente opuesta a las energías creativas que animaban a artistas como Adolfo Samper y Ernesto Franco y sus diagnosticos de los efectos que tuvo la modernización sobre la ciudadanía Bogotana. QP, Todo va a estar bien y iNos vamos! desenfocan los hitos y costumbres nacionales que el viajero consume, poniendo en crisis el proceso de auto-identificación del cual dependían historietas de Mojicón, Don Amacise, Misia Escopetica y Copetín. Y si los personajes de Samper y Franco llamaban al lector de historietas a reirse mientras pensaban yo no soy como Mojicón» o sí conozco a una Misia Escopetica», las historias escurridizas de Power Paola son y no son sobre ella o nadie en particular. Lo que queda entre manos para el lector de sus novelas gráficas es el espacio local transformado, la esfera pública usada para momentos privados, la experiencia talada hasta el núcleo que utilizan el campo de la modernidad latinoamericana (desarrollista, mestiza, capitalista y supuestamente homogénea) que sirvió de andamiaje al origen de la historieta colombiana para en 
vez de identificar lo que es propiamente colombiano (o peruano o argentino), evitar participar en los movimientos turísticos de las clases altas y media altas privilegiadas del mundo occidental mediante imágenes de cotidianidad y labor. Power Paola tal vez no lo sabía en el momento que lo vivió, pero las historias de $Q P$, Todo va a estar bien y iNos vamos! hacen de toda su obra diarios de viaje, estampas de su uso del tiempo y del trabajo, ya que aparece dictando cursos o haciendo arte en las tres. Pero más importante aún, su obra completa apuntala lo que cada una de ellas insinúan por su cuenta: sus libros no son tan solo una colección de eventos disimilares cuyos protagonistas divagan y deambulan sin propósito alguno, sino que reflejan el principio de una carrera, el proceso de profesionalización que llevó a la artista a descubrir que vivir, viajar, dibujar y escribir es trabajo y que ella no anda de vacaciones.

\section{Bibliografía}

Alemán, Gabriela. Un antivirus tropical: Powerpaola por fin llega a Ecuadon», www.labarraespaciadora.com/entrevistas/un-antivirus-tropical-powerpaola-llega-porfin-a-ecuador/. Accesado 14 de febrero, 2021.

El tío Berni. Entrevista con PowerPaola.» Entrecomics, www.entrecomics.com/2013/04/entrevista-conpowerpaola/. Accesado 14 de febrero, 2021.

Foster, David William. The Bar as Theatrical Heterotopia: José Muñoz and Carlos Sampayo's El Bar de
Joe.» El Eternauta, Daytripper and Beyond, U of Texas P, 2016, pp. 20-32.

Foucault, Michel. Of Other Spaces: Utopias and Heterotopias.» Trad. Jay Miskowiec, Diacritics

Vol. 16.1, 1967.

Gaviria, Paola. ¡Nos vamos! La Silueta Ediciones, 2016.

- QP: Éramos nosotros. Editorial Común, 2015.

- Todo va a estar bien. La Silueta Ediciones, 2015.

- Virus tropical. Editorial Común, 2014.

González Aranda, Beatriz. Caricatura 'a sangre y fuego'». La Caricatura en Colombia a Partir de la Independencia, www.banrepcultural.org/la-caricatura-en-colombia/texto17.html. Accesado 14 de febrero, 2021.

Guerra, Pablo. Historieta colombiana de prensa Adolfo Samper y sus personajes». El Globoscopio, www.elgloboscopio.com/2017/04/historietacolombiana-de-prensa-adolfo.html. Accesado 14 de febrero, 2021.

Hernández, Richard. Cómics: ¿Cómo surgieron en Colombia?». Radio Nacional de Colombia, www.radionacional.co/noticias/historia-comic-colombia. Accesado 14 de febrero, 2021.

Kincaid, Jamaica. A Small Place. Farrar, Straus and Giroux, 1988.

Lefèvre, Pascal. The Constructions of Space in Comics.» A Comics Studies Reader. Ed. por Jeet Heer y Kent Worcester, UP de Mississippi, 2009, pp. 157-62.

McCloud, Scott. Understanding Comics: The Invisible Art. Harper Collins, 1994. 